\title{
Preoxygenation with the Mapleson D system requires higher oxygen flows than Mapleson A or circle systems
}

\author{
[La préoxygénation avec le système Mapleson D requiert un débit d'oxygène plus
} élevé que les systèmes Mapleson A ou en cercle]

Samar Taha MD, Mohamad El-Khatib PhD FAARC, Sahar Siddik-Sayyid MD FRCA, Carla Dagher MD, Jules-Marie Chehade MD, Anis Baraka MD FRCA

Purpose: This study investigates the efficacy of preoxygenation with Mapleson A and Mapleson D breathing systems vs the circle system with $\mathrm{CO}_{2}$ absorber.

Methods: Thirteen healthy volunteers underwent tidal volume breathing for three minutes via facemask using Mapleson $\mathrm{A}$, Mapleson $\mathrm{D}$ breathing systems or the circle system with $\mathrm{CO}_{2}$ absorber while breathing $100 \% \mathrm{O}_{2}$ at flow rates of $5 \mathrm{~L} \cdot \mathrm{min}^{-1}$ and $10 \mathrm{~L} \cdot \mathrm{min}^{-1}$. Each volunteer acted as his/her own control by going through each of six preoxygenation protocols in random order. Fractional end-tidal $\mathrm{O}_{2}$ concentration $\left(\mathrm{F}_{\mathrm{ETO} 2}\right)$ was measured at $30-\mathrm{sec}$ intervals. The results were compared among the three anesthesia systems at the two fresh gas flow rates.

Results: At a fresh gas flow rate of $5 \mathrm{~L} \cdot \mathrm{min}^{-1}$, the Mapleson A and circle systems achieved $\mathrm{F}_{\mathrm{ETO} 2}$ values of $90.8 \pm 1.4 \%$ and $90.0 \pm 1.1 \%$, respectively, compared with the lower $F_{\mathrm{ETO} 2}$ $(81.5 \pm 6.3 \%, P<0.05)$, achieved with the Mapleson D system. When breathing $\mathrm{O}_{2}$ at $10 \mathrm{~L} \cdot \mathrm{min}^{-1}$, the $\mathrm{F}_{\mathrm{ETO} 2}$ values after three minutes were similar with the Mapleson A, circle, and Mapleson D breathing systems (91.8 $\pm 2.3 \%, 91.2 \pm 1.7 \%$, $90.6 \pm 2.7 \%$, respectively).

Conclusion: When using the Mapleson A and the circle systems for preoxygenation, an oxygen flow rate of $5 \mathrm{~L} \cdot \mathrm{min}^{-1}$ can adequately preoxygenate the patient within three minutes, while an oxygen flow of $10 \mathrm{~L} \cdot \mathrm{min}^{-1}$ is required to achieve a similar fractional end-tidal $\mathrm{O}_{2}$ concentration with the Mapleson D system.
Objectif : Cette étude examine l'efficacité de la préoxygénation avec les systèmes de respiration Mapleson $A$ et $D$ vs le circuit en cercle avec chaux sodée.

Méthode : Treize volontaires sains ont respiré à volume courant durant trois minutes via un masque facial, en utilisant les systèmes de respiration Mapleson A, Mapleson D ou en circuit en cercle avec chaux sodée, en respirant $100 \% \mathrm{O}_{2}$ à des débits de $5 \mathrm{~L} \cdot \mathrm{min}^{-1}$ et 10 $L \cdot \mathrm{min}^{-1}$. Chaque volontaire $a$ été son propre témoin en parcourant six protocoles de préoxygénation dans un ordre aléatoire. La concentration fractionnelle d'O $\mathrm{O}_{2}$ télé-expiratoire $\left(F_{\mathrm{ETO} 2}\right)$ a été mesurée à intervalles de $30 \mathrm{sec}$. Les résultats ont été comparés dans les trois systèmes d'anesthésie aux deux débits de gaz frais.

Résultat : À un débit de gaz frais de $5 \mathrm{~L} \cdot \mathrm{min}^{-1}$, on a atteint des valeurs de $F_{\text {ETO2 }}$ de 90,8 $\pm 1,4 \%$ et $90,0 \pm 1,1 \%$ avec le système Mapleson A et le circuit en cercle, respectivement, et une $F_{E T O 2}$ plus faible $(81,5 \pm 6,3 \%, P<0,05)$ avec le système Mapleson $D$. Après trois minutes de respiration d' $\mathrm{O}_{2}$ à $10 \mathrm{~L} \cdot \mathrm{min}^{-1}$, les valeurs de $F_{E T O 2}$ étaient semblables pour les systèmes de respiration Mapleson A, le circuit en cercle et Mapleson D (91,8 $\pm 2,3 \%$, 91,2 \pm I,7 \%, 90,6 \pm 2,7 \%, respectivement).

Conclusion : Lorsqu'on utilise le système de respiration Mapleson $A$ ou le circuit en cercle pour la préoxygénation, un débit d'oxygène de $5 \mathrm{~L} \cdot \mathrm{min}^{-1}$ peut préoxygéner le patient de façon adéquate en trois minutes, alors qu'un débit d'oxygène de $10 \mathrm{~L} \cdot \mathrm{min}^{-1}$ est requis pour atteindre une concentration fractionnelle d' $\mathrm{O}_{2}$ télé-expiratoire semblable avec le système Mapleson D.

CAN J ANESTH 2007 / 54: 2 / pp 141-145

From the Department of Anesthesiology, American University of Beirut Medical Center, Beirut, Lebanon. Address correspondence to: Dr. Anis Baraka, Professor and Chairman, Department of Anesthesiology, American University of Beirut

Medical Center, P.O. Box 110236 Beirut, Beirut, Lebanon. Phone: 9611 350000, ext. 6380; E-mail: abaraka@aub.edu.lb Accepted for publication November 8, 2006.

Revision accepted November 16,2006.

Competing interest: None declared. 
$\mathrm{P}$ REOXYGENATION essentially depends on denitrogenation of the functional residual capacity (FRC) of the patient's lungs and replacing the nitrogen with oxygen. Hamilton and Eastwood have shown that denitrogenation is $95 \%$ complete within two to three minutes when breathing 100\% oxygen using the circle $\mathrm{CO}_{2}$ absorber system at a fresh gas flow (FGF) rate of 5 $\mathrm{L} \cdot \mathrm{min}^{-1}$ and tidal volume breathing. ${ }^{1}$ Monitoring preoxygenation by measuring fractional end-tidal oxygen concentration $\left(\mathrm{F}_{\mathrm{ETO} 2}\right)$ is probably the best surrogate marker of lung denitrogenation. ${ }^{2-4}$

Mapleson suggested that the degree of rebreathing during spontaneous breathing is less with Mapleson A system than with Mapleson D system. ${ }^{5}$ Such differences in the degree of rebreathing may affect the efficacy of preoxygenation. This study was designed to investigate the hypothesis that oxygen flow and anesthetic system type may influence the efficacy of preoxygenation.

\section{Methods}

The study was approved by the institutional Research Ethics Board and informed consent was obtained from all volunteers prior to their participation in the study. Thirteen non-smoking healthy subjects (five females and eight males) with no history of heart or lung disease were enrolled. Subjects were not recruited if they were edentulous or if they had a beard. Also excluded were individuals $<20$ or $>40 \mathrm{yr}$ of age, and those who weighed $<55 \mathrm{~kg}$ or $>90 \mathrm{~kg}$.

The subjects were asked to lie supine, and were familiarized with the procedures by breathing normally while maintaining a tight-fitting facemask. A pulse oximeter (Novametrix, Wallingford, CT, USA) was applied to a finger tip for continuous monitoring of oxygen saturation.

A standard anesthesia machine (Datex ADU AS/3 Anesthesia Monitor, Helsinki, Finland) was used throughout the study. Three anesthetic systems were investigated: the circle system, an adult Mapleson A system (Magill system) and an adult Mapleson D system. The Mapleson A and Mapleson D systems consisted of $107 \mathrm{~cm}$ corrugated tubes and a $2-\mathrm{L}$ capacity breathing bag. The circle system consisted of an absorber (Datex-Ohmeda Compact Absorber containing $550 \mathrm{~g}$ of soda lime), two $150-\mathrm{cm}$ corrugated breathing tubes, and a 2 -L capacity breathing bag. Prior to each preoxygenation trial, the anesthesia systems were flushed for five minutes with $100 \% \mathrm{O}_{2}$ at a flow rate of $10 \mathrm{~L} \cdot \mathrm{min}^{-1}$ to eliminate any residual air or nitrous oxide.

The reservoir bag was fully inflated using the oxy-

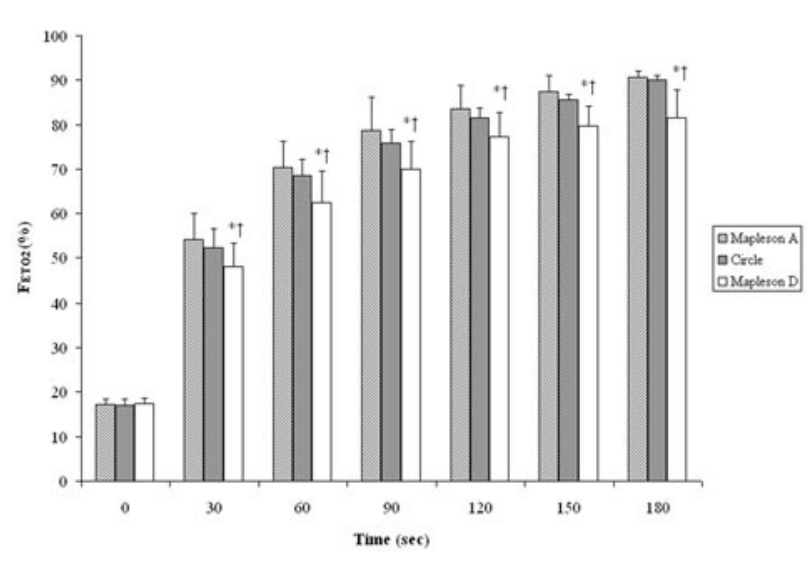

FIGURE 1 The fractional end-tidal oxygen concentrations $\left(\mathrm{F}_{\mathrm{ETO} 2}\right)$ for the Mapleson A, the circle, and the Mapleson $\mathrm{D}$ anesthesia systems during preoxygenation with $100 \% \mathrm{O}_{2}$ for three minutes at a fresh gas flow rate of $5 \mathrm{~L} \cdot \mathrm{min}^{-1} .{ }^{*} P<$ 0.05 vs Mapleson A system; $\dagger P<0.05$ vs circle system.

gen flush, and the mask was partially occluded with the palm of the hand. Preoxygenation was performed with $100 \% \mathrm{O}_{2}$ and a tight fitting facemask. Tidal volume breathing for three minutes was performed using the three anesthetic systems, while subjects breathed $100 \% \mathrm{O}_{2}$ at $\mathrm{FGF}$ rates of $5 \mathrm{~L} \cdot \mathrm{min}^{-1}$ and $10 \mathrm{~L} \cdot \mathrm{min}^{-1}$ in random order. Each volunteer acted as his/her own control by going through each of six protocols of preoxygenation in a random order, separated by rest periods of five minutes breathing room air. The randomization sequence was computer-generated.

Side stream respiratory gases were sampled from a sampling port placed next to the mask and filter. Measurements of inspired fraction of oxygen $\left(\mathrm{F}_{\mathrm{I}} \mathrm{O}_{2}\right)$ and $\mathrm{F}_{\mathrm{ETO} 2}$ were recorded using a calibrated gas monitor (Datex ADU AS/3 Anesthesia Monitor, Helsinki, Finland). Calibration with known gas mixtures was carried out according to the manufacturer's specifications.

Sample size calculation was based upon an expected clinically significant change in $\mathrm{F}_{\mathrm{ETO} 2}$ of $10 \%$. Assuming a type I error of $5 \%$ and a type II error of $10 \%$, with a standard deviation estimate of $10 \%$ derived from a pilot study, at least ten subjects were needed for the study. For all subjects, the $\mathrm{F}_{\mathrm{I}} \mathrm{O}_{2}$ and the $\mathrm{F}_{\mathrm{ETO} 2}$ values were collected during tidal volume breathing at 30-sec intervals during preoxygenation for a period of three minutes. The means and standard deviations of the $\mathrm{F}_{\mathrm{I}} \mathrm{O}_{2}$ and the $\mathrm{F}_{\mathrm{ETO} 2}$ values obtained with the Mapleson A, the Mapleson D, and the circle systems at each 30sec interval (i.e., at $30 \mathrm{sec}, 60 \mathrm{sec}, 90 \mathrm{sec}, 120 \mathrm{sec}, 150$ 


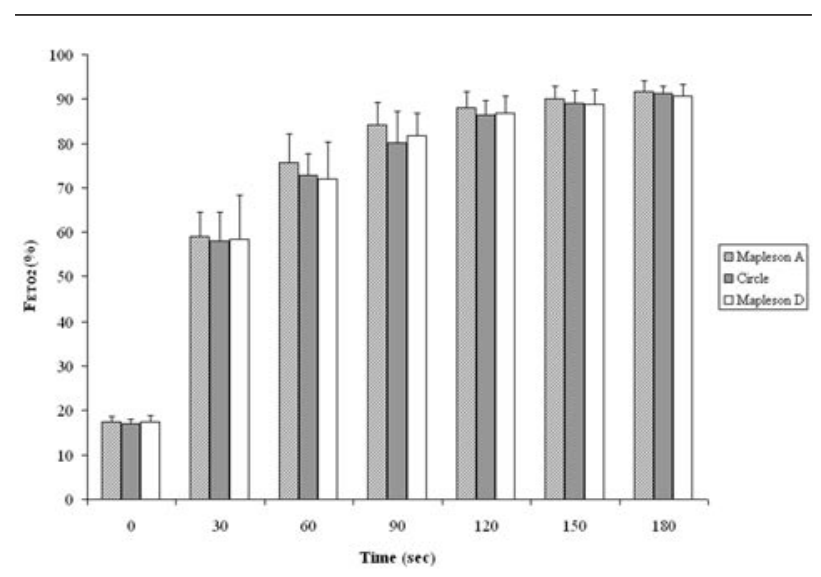

FIGURE 2 The fractional end-tidal oxygen concentrations $\left(\mathrm{F}_{\mathrm{ETO} 2}\right)$ for the Mapleson $\mathrm{A}$, the circle, and the Mapleson D anesthesia systems during preoxygenation with $100 \% \mathrm{O}_{2}$ for three minutes at a fresh gas flow rate of $10 \mathrm{~L} \cdot \mathrm{min}^{-1}$.

sec, and $180 \mathrm{sec}$ ) were compared at $\mathrm{O}_{2}$ flow rates of 5 $\mathrm{L} \cdot \mathrm{min}^{-1}$ and $10 \mathrm{~L} \cdot \mathrm{min}^{-1}$ using a paired Student's $t$ test and repeated measures ANOVA with the Dunnett's correction for post hoc analysis. Also, non-linear regression analysis was used for assessing the changes in $\mathrm{F}_{\mathrm{ETO} 2}$ over time and the respective correlation coefficients were determined. Statistical significance was assumed when $P<0.05$.

\section{Results}

All subjects completed all six phases of the study protocol. Using an $\mathrm{O}_{2}$ flow of $5 \mathrm{~L} \cdot \mathrm{min}^{-1}$, the $\mathrm{F}_{\mathrm{I}} \mathrm{O}_{2}$ increased to maximal levels of $96.0 \pm 2.7 \%$ and $94.8 \pm 3.7 \%$ within $30 \mathrm{sec}$ of preoxygenation with the Mapleson A system and the circle system, respectively. However, with the Mapleson D system, the $\mathrm{F}_{1} \mathrm{O}_{2}$ at $30 \mathrm{sec}$ was significantly lower $(86.7 \pm 8.3 \%)$ as compared to the Mapleson A and the circle systems. At an $\mathrm{O}_{2}$ flow of $10 \mathrm{~L} \cdot \mathrm{min}^{-1}$, the $\mathrm{F}_{1} \mathrm{O}_{2}$ increased in the Mapleson A, the circle, and the Mapleson D systems within $30 \mathrm{sec}$ of preoxygenation, up to $98.3 \pm 1.2 \%, 98.1 \pm 0.8 \%$, and $97.6 \pm 1.9 \%$ respectively, with no significant differences among the three systems.

Using an $\mathrm{O}_{2}$ flow of $5 \mathrm{~L} \cdot \mathrm{min}^{-1}$, the $\mathrm{F}_{\mathrm{ETO} 2}$ values increased significantly from a baseline value of 17.2 $\pm 1.2 \%$ to $90.8 \pm 1.4 \%$ after three minutes of preoxygenation with the Mapleson A system, and from a baseline of $17.1 \pm 1.3 \%$ to $90.0 \pm 1.1 \%$ with the circle $\mathrm{CO}_{2}$ absorber system. Also, after three minutes of preoxygenation, the $\mathrm{F}_{\mathrm{ETO} 2}$ value with the Mapleson $\mathrm{D}$ system was $81.5 \pm 6.3 \%$, which was lower $(P=0.001)$ than that achieved with the Mapleson A system (90.8

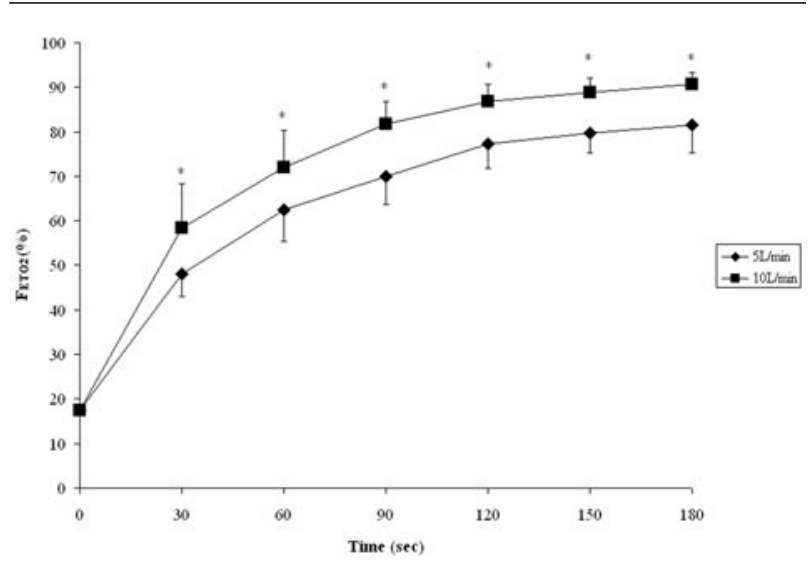

FIGURE 3 The fractional end-tidal oxygen concentration $\left(\mathrm{F}_{\mathrm{ETO} 2}\right)$ with the Mapleson D system during preoxygenation with $100 \% \mathrm{O}_{2}$ for three minutes at fresh gas flow rates of 5 $\mathrm{L} \cdot \mathrm{min}^{-1}$ vs $10 \mathrm{~L} \cdot \mathrm{min}^{-1}$. ${ }^{*} P<0.05$ vs $10 \mathrm{~L} \cdot \mathrm{min}^{-1}$.

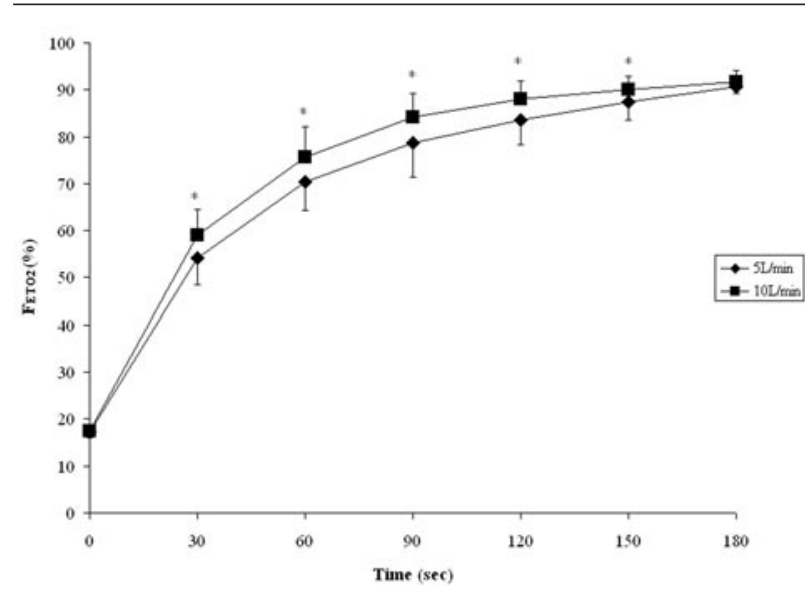

FIGURE 4 The fractional end-tidal oxygen concentration $\left(\mathrm{F}_{\mathrm{ETO} 2}\right)$ with the Mapleson A anesthesia system during preoxygenation with $100 \% \mathrm{O}_{2}$ for three minutes at fresh gas flow rates of $5 \mathrm{~L} \cdot \mathrm{min}^{-1}$ vs $10 \mathrm{~L} \cdot \mathrm{min}^{-1}$. ${ }^{*} P<0.05$ vs 10 $\mathrm{L} \cdot \mathrm{min}^{-1}$.

$\pm 1.4 \%)$ and the circle absorber system $(90.0 \pm 1.1 \%)$ (Figure 1). The $\mathrm{F}_{\mathrm{ETO} 2}$ values at each time interval and after three minutes of preoxygenation were not different between the Mapleson A and the circle system. In contrast, when the Mapleson D system was used, the $\mathrm{F}_{\mathrm{ETO2} 2}$ at each time interval throughout the preoxygenation period was significantly lower than that achieved with both the Mapleson A and the circle absorber systems. 


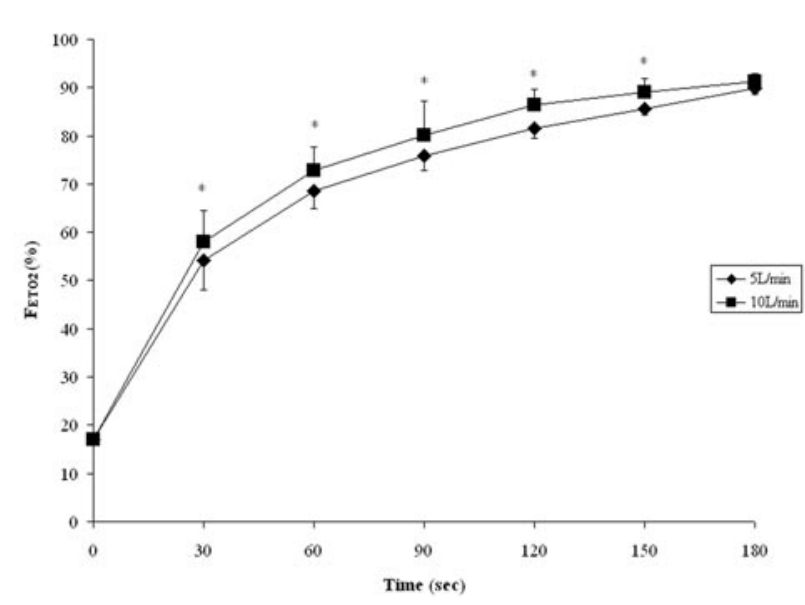

FIGURE 5 The fractional end-tidal oxygen concentration $\left(\mathrm{F}_{\mathrm{ETO2}}\right)$ with the circle system during preoxygenation with $100 \% \mathrm{O}_{2}$ for three minutes at fresh gas flow rates of 5 $\mathrm{L} \cdot \mathrm{min}^{-1}$ ps $10 \mathrm{~L} \cdot \mathrm{min}^{-1}$. ${ }^{*} P<0.05$ ps $10 \mathrm{~L} \cdot \mathrm{min}^{-1}$.

Using an $\mathrm{O}_{2}$ flow of $10 \mathrm{~L} \cdot \mathrm{min}^{-1}$ for preoxygenation, the $\mathrm{F}_{\mathrm{ETO} 2}$ values increased at all time intervals throughout the preoxygenation period with the three systems. After three minutes, the $\mathrm{F}_{\mathrm{ETO} 2}$ values were not significantly different when comparing the Mapleson A, the circle system, and the Mapleson D systems $(91.8 \pm 2.3 \%, 91.2 \pm 1.7 \%, 90.6 \pm 2.7 \%$ respectively $)$ (Figure 2). At an $\mathrm{O}_{2}$ flow of $10 \mathrm{~L} \cdot \mathrm{min}^{-1}$, the $\mathrm{F}_{\mathrm{ETO} 2}$ with the Mapleson D system at $180 \mathrm{sec}(90.6 \pm 2.7 \%)$ was not significantly different from the $\mathrm{F}_{\mathrm{ETO} 2}$ values of the Mapleson A and the circle absorber systems at 180 sec when using an $\mathrm{O}_{2}$ flow of $5 \mathrm{~L} \cdot \mathrm{min}^{-1}(90.8 \pm 1.42 \%$ and $90.0 \pm 1.1 \%$ respectively).

Comparing the rate of preoxygenation for each system at $5 \mathrm{~L} \cdot \mathrm{min}^{-1}$ vs $10 \mathrm{~L} \cdot \mathrm{min}^{-1}$ showed that when using the Mapleson $\mathrm{D}$ system increasing the $\mathrm{O}_{2}$ flow from $5 \mathrm{~L} \cdot \mathrm{min}^{-1}$ to $10 \mathrm{~L} \cdot \mathrm{min}^{-1}$ resulted in significant increases in $\mathrm{F}_{\mathrm{ETO} 2}$ values at $30,60,90,120,150$, and $180 \mathrm{sec}$ throughout the preoxygenation period (Figure 3). However, with the Mapleson A system, increasing the $\mathrm{O}_{2}$ flow from $5 \mathrm{~L} \cdot \mathrm{min}^{-1}$ to $10 \mathrm{~L} \cdot \mathrm{min}^{-1}$ increased the $\mathrm{F}_{\mathrm{ETO2}}$ values at $30,60,90,120$, and $150 \mathrm{sec}$ during the preoxygenation period, resulting in similar $\mathrm{F}_{\mathrm{ETO} 2}$ values at $180 \mathrm{sec}$ (Figure 4). Also, with the circle absorber system, increasing the $\mathrm{O}_{2}$ flow from $5 \mathrm{~L} \cdot \mathrm{min}^{-1}$ to $10 \mathrm{~L} \cdot \mathrm{min}^{-1}$ increased the $\mathrm{F}_{\mathrm{ETO} 2}$ values at $30,60,90,120$, and $150 \mathrm{sec}$ during the preoxygenation period, resulting in similar $\mathrm{F}_{\mathrm{ETO} 2}$ values at $180 \mathrm{sec}$ (Figure 5).

The $\mathrm{F}_{\mathrm{ETO} 2}$ increased exponentially over time with the Mapleson D $\left(\mathrm{r}^{2}=0.998\right)$ (Figure 3), the Mapleson $\mathrm{A}\left(\mathrm{r}^{2}=0.999\right)($ Figure 4$)$, and the circle $\left(\mathrm{r}^{2}=0.998\right)$
(Figure 5) systems. The most significant increases in $\mathrm{F}_{\mathrm{ETO} 2}$ with all three systems occurred during the first 60 to $90 \mathrm{sec}$ of preoxygenation (Figure 2).

\section{Discussion}

The present report shows that with an $\mathrm{O}_{2}$ flow of $5 \mathrm{~L} \cdot \mathrm{min}^{-1}$, the $\mathrm{F}_{\mathrm{ETO} 2}$ achieved with the Mapleson D system after three minutes of preoxygenation is significantly lower than that achieved by the Mapleson $\mathrm{A}$ and the circle $\mathrm{CO}_{2}$ absorber systems. Increasing the $\mathrm{O}_{2}$ flow to $10 \mathrm{~L} \cdot \mathrm{min}^{-1}$ improved both the $\mathrm{F}_{\mathrm{I}} \mathrm{O}_{2}$ and the $\mathrm{F}_{\mathrm{ETO} 2}$ values obtained with the Mapleson $\mathrm{D}$ system to the same levels achieved by using an $\mathrm{O}_{2}$ flow of $5 \mathrm{~L} \cdot \mathrm{min}^{-1}$ with the Mapleson A and the circle $\mathrm{CO}_{2}$ absorber systems. The decreased $\mathrm{F}_{\mathrm{ETO} 2}$ with the Mapleson D anesthesia system at $5 \mathrm{~L} \cdot \mathrm{min}^{-1}$ can be attributed to a higher degree of rebreathing, as reflected by the lower $\mathrm{F}_{\mathrm{I}} \mathrm{O}_{2}$ levels throughout the preoxygenation period.

Preoxygenation depends on spontaneous breathing of $100 \% \mathrm{O}_{2}$ in order to denitrogenate the FRC of the lungs and to increase the $\mathrm{O}_{2}$ stores in the FRC. Hamilton and Eastwood have shown that denitrogenation is $95 \%$ complete in two to three minutes at an $\mathrm{O}_{2}$ flow of $5 \mathrm{~L} \cdot \mathrm{min}^{-1}$ and tidal volume breathing using the circle $\mathrm{CO}_{2}$ absorber system. ${ }^{1}$ Other anesthesia systems such as the Mapleson A (Magill system), and Mapleson D system including the Bain modification, ${ }^{6}$ may also be used for preoxygenation.

On a theoretical basis, Mapleson suggested that rebreathing during spontaneous ventilation may be less with the Mapleson A system compared to Mapleson D system. ${ }^{5}$ With the Mapleson A system, the FGF is delivered distally near the reservoir bag, while the overflow valve is located proximally near the patient end of the system, which decreases the degree of rebreathing. In contrast, with the Mapleson D system, the FGF is delivered proximal to the patient, while the outlet valve is distally located near the reservoir bag, which increases the possibility of rebreathing. Baraka et al. have shown in spontaneously breathing children that a FGF equal to one-minute volume can adequately prevent $\mathrm{CO}_{2}$ rebreathing when using the Mapleson A system. ${ }^{7}$ In contrast, a FGF equivalent to two-minute volumes is required to eliminate rebreathing when the Mapleson D system is used. ${ }^{7}$ In adult patients using the Magill system, Kain $e t$ al. have even shown that a FGF equivalent to alveolar ventilation volume can adequately prevent rebreathing. ${ }^{8}$ The circle system includes unidirectional inspiratory and expiratory valves that can minimize rebreathing of exhaled gases and subsequently improve the rate of preoxygenation. 
The degree of rebreathing as monitored by the $\mathrm{F}_{\mathrm{I}} \mathrm{O}_{2}$ using the different anesthesia systems can affect the washout of exhaled nitrogen from the FRC and hence may explain our results concerning preoxygenation by the different anesthesia systems as evidenced by the $\mathrm{F}_{\mathrm{ETO2}}$. Thus, using an $\mathrm{O}_{2}$ flow equivalent to one alveolar minute ventilation volume in adults (i.e., $5 \mathrm{~L} \cdot \mathrm{min}^{-1}$ ) provides adequate preoxygenation within three minutes when the Mapleson A and the circle absorber systems are used. In contrast, when the Mapleson D system is used, an $\mathrm{O}_{2}$ flow equivalent to two alveolar minute ventilation volumes (i.e., 10 $\mathrm{L} \cdot \mathrm{min}^{-1}$ ) is required to achieve the same degree of preoxygenation.

The $\mathrm{F}_{\mathrm{ETO} 2}$ increased exponentially over time during preoxygenation with the three anesthesia systems. This exponential increase in $\mathrm{F}_{\mathrm{ETO} 2}$ is equivalent to, and mirrors the exponential wash-out of nitrogen during the preoxygenation period. ${ }^{9}$ In the present report using tidal volume breathing and an $\mathrm{O}_{2}$ flow of 10 $\mathrm{L} \cdot \mathrm{min}^{-1}$ with all three systems, the most significant rate of increase in $\mathrm{F}_{\mathrm{ETO} 2}$ up to and greater than $70 \%$, occurred within the first 60 to $90 \mathrm{sec}$ of the preoxygenation period.

In conclusion, the present report shows that when using the Mapleson A and the circle $\mathrm{CO}_{2}$ absorber systems for preoxygenation, an $\mathrm{O}_{2}$ flow of $5 \mathrm{~L} \cdot \mathrm{min}^{-1}$ can adequately preoxygenate the patient by tidal volume breathing within three minutes, while an $\mathrm{O}_{2}$ flow of $10 \mathrm{~L} \cdot \mathrm{min}^{-1}$ is required to achieve a similar fractional end-tidal $\mathrm{O}_{2}$ concentration with the Mapleson D system.

\section{References}

1 Hamilton WK, Eastwood DW. A study of denitrogenation with some inhalation anesthetic systems. Anesthesiology 1955; 16: 861-7.

2 Myles PS, Heap M, Langley M. Agreement between end-tidal oxygen concentration and the alveolar gas equation: pre and post cardiopulmonary bypass. Anaesth Intensive Care 1993; 21: 240-1.

3 Gagnon C, Fortier LP, Donati F. When a leak is unavoidable, preoxygenation is equally ineffective with vital capacity or tidal volume breathing. Can J Anesth 2006; 53: 86-91.

4 Baraka AS, Taha SK, El-Khatib MF, Massouh FM, Jabbour DG, Alameddine MM. Oxygenation using tidal volume breathing following maximal exhalation. Anesth Analg 2003; 97: 1533-5.

5 Mapleson $W W$. The elimination of rebreathing in various semi-closed anaesthetic systems. Br J Anaesth 1954; 26: 323-32.

6 Rooney MJ. Pre-oxygenation: a comparison of two techniques using a Bain system. Anaesthesia 1994; 49: 629-32.

7 Baraka A, Brandstater B, Muallem M, Seraphim C. Rebreathing in a double T-piece system. Br J Anaesth 1969; 41: 47-53.

8 Kain ML, Nunn JF. Fresh gas economics of the Magill circuit. Anesthesiology 1968; 29: 964-74.

9 Olegard C, Sondergaad S, Houltz E, Lundin S, Stenqvist $O$. Estimation of functional residual capacity at the bedside using standard monitoring equipment: a modified nitrogen washout/washin technique requiring a small change of the inspired oxygen fraction. Anesth Analg 2005; 101: 206-12. 